\section{Angel Dust}

T. Arndt

Bioscientia Institut für Medizinische Diagnostik $\mathrm{GmbH}$, Ingelheim, Deutschland
Definition Straßenname/Deckname für P Phencyclidin ( $\triangleright$ Straßennamen von Drogen: Phencyclidin) 